\title{
Recomendaciones para el diagnóstico y tratamiento etiológico de la faringoamigdalitis aguda estreptocócica en pediatría
}

\section{Recommendations for diagnosis and etiological treatment of acute streptococcal pharyngotonsilitis in pediatrics}

\author{
Regina Pérez, Daniela Pavez, Jaime Rodríguez y José Cofré, en representación del \\ Comité de Antimicrobianos. Sociedad Chilena de Infectología. 2018
}

\section{Introducción}

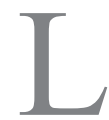

a faringoamigdalitis aguda (FA) es uno de los motivos de consulta más frecuentes para pediatras, internistas y médicos de atención primaria.

Aunque Streptococcus pyogenes, también denominado Streptococcus $\beta$ hemolítico del grupo A (SBHGA), es la causa bacteriana más común de $\mathrm{FA}$, sólo una pequeña proporción de pacientes con esta condición se encuentra infectado por este agente.

La presentación clínica de la FA estreptocócica (FAE) se sobrepone con otras causas (p. ej.: virales) siendo fundamental su confirmación microbiológica (recomendación de SLIPE, AAP, IDSA, CDC*).

\section{Definiciones}

- Faringitis: inflamación de la faringe, con o sin compromiso de amígdalas, adenoides, mucosa nasal, úvula y paladar blando, habitualmente producida por virus.

- Amigdalitis: inflamación de las amígdalas debido a infecciones (virales o bacterianas); generalmente se presenta con exudado amigdalino y/o adenopatías cervicales.

- Faringoamigdalitis estreptocócica: inflamación de amígdalas causada por SBHGA, que puede afectar los alrededores de la faringe. Esta definición no incluye la condición de portador de SBHGA que, por su naturaleza, es asintomático.

\section{Otras etiologías de faringitis y/o faringoamigdalitis}

\section{Infecciosas}

Dentro de los agentes etiológicos descritos de faringitis y/o FA se encuentran:

- Virus respiratorios: $50-80 \%$, son la causa más frecuente de faringitis y/o FA (adenovirus, virus influenza, virus parainfluenza, rinovirus, virus respiratorio sincicial).

- Streptococcus $\beta$ hemolíticos de los grupos $\mathrm{C}$ y G: $<5-20 \%$.

- Virus de Epstein Barr: 1-10\% (como parte de un cuadro sistémico).

- Otros virus: coxsackie, echovirus, herpes simplex tipo $1 \mathrm{y}$, como parte de un cuadro sistémico: citomegalovirus, rubéola, sarampión, virus de inmunodeficiencia humana.

- Otras bacterias: Chlamydia pneumoniae, Staphylococcus aureus, Corynebacterium diphtheriae, Mycoplasma pneumoniae, Neisseria gonorrhoeae, Arcanobacterium haemolyticum, Fusobacterium necrophorum: $<5 \%$.

\section{No infecciosas}

PFAPA (sigla en inglés para: síndrome de fiebre periódica, estomatitis aftosa, faringitis y adenitis), enfermedad de Kawasaki, exudación post adenoamigdalectomía (exudado fibrinoso/pseudomembranoso), agranulocitosis.

Tonsilolitos (suelen confundirse con exudado).

\section{Epidemiología}

La infección por SBHGA es infrecuente bajo 3 años de edad, afecta principalmente a niños de edad escolar y adolescentes, entre 5 y 15 años.

Es una infección ubicua, más frecuente en climas templados, usualmente ocurre en invierno e inicios de primavera.

Se asocia, con mayor frecuencia, a condiciones de hacinamiento en poblaciones con problemas socioeconómicos; el contacto cercano facilita la transmisión (escuelas, guarderías, hogares de menores).

Dependiendo de la situación epidemiológica, la tasa de portadores faríngeos de SBHGA en niños puede ser hasta $15 \%$, pudiendo llegar hasta $20 \%$ en adultos y $50 \%$ en niños contactos con SBHGA en situación de brote de enfermedad estreptocócica.

\footnotetext{
* SLIPE: Sociedad Latinoamericana de Infectología Pediátrica. AAP: American Academy of Pediatrics. IDSA: Infectious Diseases Society of America. CDC: Centers for Disease Control and Prevention.
} 


\section{Fuente de infección}

El contagio ocurre por contacto cercano con persona con FAE; en brotes de FAE en escolares, se ve facilitado el contacto con secreciones respiratorias del caso índice.

La máxima transmisibilidad ocurre durante la fase sintomática de la infección.

El período de incubación de la FAE es de 2 a 5 días post-exposición a SBHGA.

Más de la mitad de los contactos que adquieren el microorganismo se enfermará.

La adquisición asintomática de SBHGA puede plantear cierto riesgo de complicaciones no supurativas; sin embargo, frente a esta remota posibilidad y baja transmisibilidad, no se recomienda la búsqueda microbiológica en contactos domiciliarios asintomáticos.

Algunos hospederos padecen de esta afección en forma recurrente, tendencia que podría explicarse por la existencia de receptores microbianos en la mucosa del anillo linfático de Waldeyer (moléculas de histocompatibilidad mayor tipo IIl, receptor CD44, moléculas de fibronectina y ácido siálico).

\section{Manifestaciones clínicas}

Existe una amplia superposición entre signos y síntomas de FAE y no estreptocócica (generalmente viral y ocasionalmente de causa no infecciosa), siendo la capacidad de identificar en forma certera una FAE sólo basado en elementos clínicos, aún en manos de expertos, muy limitada. En la Tabla 1 se esquematiza una aproximación semiológica a la etiología de una FA.

En los casos de FAE, además, se pueden presentar calofríos y compromiso del estado general. Existe un espectro de enfermedad desde síntomas leves a faringitis exudativa

Tabla 1. Características clínicas y epidemiológicas sugerentes de FAE versus viral que orientan el diagnóstico etiológico

FAE

Faringitis viral

Edad 5-15 años

Presentación en invierno e inicio primavera

Historia de contacto con FAE

$\begin{array}{ll}\text { Síntomas } & \text { Síntomas } \\ \text { Odinofagia de inicio súbito } & \text { Coriza } \\ \text { Fiebre }>38^{\circ} \mathrm{C} & \text { Disfonía } \\ \text { Cefalea } & \text { Tos } \\ \text { Náuseas, vómitos, dolor abdominal } & \text { Diarrea } \\ & \\ \text { Signos } & \text { Signos } \\ \text { Inflamación faringoamigdalina } & \text { Conjuntivitis } \\ \text { Exudado faringoamigdalino } & \text { Exantema maculopapular } \\ \text { Petequias en el paladar } & \text { Estomatitis ulcerativa } \\ \text { Adenitis cervical submandibular (linfonodos sensibles) } & \\ \text { Exantema propio de escarlatina } & \end{array}$

con fiebre y postración. La sintomatología se resuelve en alrededor de una semana, incluso sin tratamiento. La fiebre cede a los tres a cinco días, la mayoría de los cuadros son autolimitados, persistiendo sí la infección faríngea con el riesgo de una afección post-estreptocócica y manteniendo la contagiosidad del paciente para terceros.

\section{Faringoamigdalitis de otras etiologías}

\section{Mononucleosis infecciosa}

La presentación clínica de la infección por virus de Epstein Barr es de inicio paulatino (varios días), se acompaña de fiebre de baja cuantía, acentuada astenia y adinamia en el adolescente y preadolescente, y al examen físico se pueden encontrar: exudado amigdalino blanquecino o grisáceo bilateral, poliadenopatías cervicales, axilares e inguinales, hepatitis subclínica o clínica, compromiso obstructivo de la vía aérea alta (en preescolares) y, a veces, hepatoesplenomegalia. Suele interpretarse como FAE y la refractariedad a la terapia con $\beta$-lactámicos o la aparición de un rash máculo papular consecutivo a la administración de un $\beta$-lactámico, sugiere la posibilidad de esta etiología.

\section{Adenovirus}

Causa una FA exudativa de color blanquecino, bilateral, asociado a adenitis submaxilares bilaterales en el ángulo mandibular, fiebre muy elevada $\mathrm{y}$, en ocasiones, acompañada de conjuntivitis catarral o pesudomembranosa. Suele interpretarse como FAE y la refractariedad a la terapia con $\beta$-lactámicos sugiere la posibilidad de esta etiología.

\section{Estomatitis herpética}

Las infecciones por virus herpes simplex tipo 1 se presentan con lesiones vesiculares y exudado.

\section{Estomatitis por enterovirus}

Igualmente, las FA por enterovirus (coxsackie, echo) se manifiestan con úlceras fauciales (herpangina) y, en ocasiones, acompañadas de úlceras en el tercio anterior de la mucosa oral.

\section{Difteria}

La infección causada por Corynebacterium diphtheriae se manifiesta con una angina blanco-grisácea pseudomembranosa adherente, adenopatías cervicales prominentes, palidez, halitosis y cursa de manera afebril.

\section{Otra FA exudativa}

Arcanobacterium haemolyticum ocasiona exudado amigdalino y se asocia a un rash circinado de las extremidades superiores y el tronco, enteramente distinto que el rash escalatinoso. 


\section{Criterios diagnósticos: clínico y de laboratorio}

\section{¿Cuál es la utilidad de la semiología para el diagnóstico certero de FAE?}

Se han diseñado diversas maneras de aproximarse clínicamente a la etiología estreptocócica de una FA, comparando en forma ciega los hallazgos semiológicos en un grupo significativo de pacientes con la recuperación de $S$. pyogenes en el cultivo faríngeo. El score de Centor (1981), un método de tamizaje apropiado para orientar la etiología estreptocócica, ha sido validado para pacientes de 15 años de edad o más. El score modificado de Centor, sugerido por McIsaac (2000), corrige por edad, siendo aplicable en niños y adultos. El score de Ellen Wald (1998) para estreptococcia faríngea incorpora el factor estacionalidad.

\section{Score clínico basado en criterios de Centor}

El score original de Centor provee una estimación de probabilidad de un cultivo positivo. Contempla cuatro criterios y a la presencia de cada cual se le asigna un punto. (Tabla 2).

\section{Score de Mc Isaac}

En niños de 3 a 14 años con odinofagia ayuda a identificar apropiadamente la infección estreptocócica en forma significativa comparado con la evaluación clínica convencional (sensibilidad 96,9 vs $70,6 \%, p<0,05$ ), con reducción en el uso innecesario de antimicrobianos en $48 \%(\mathrm{p}<0,001)$ y sin aumentar la indicación de cultivo faríngeo o test rápido (Tabla 3 ).

El score tiene un valor predictor positivo (VPP) de $28-35 \%$ con 3 puntos y de $51-53 \%$ con 4 puntos.

$\mathrm{Si} \geq 4$ puntos: cultivar a todos, inicio de tratamiento empírico inmediato según sea la expresión clínica (si el paciente tiene fiebre alta o aspecto séptico con presentación precoz en el curso de la enfermedad).

Sólo en los pacientes con un score $\geq 3$ (Centor o McIsaac), es recomendado intentar la confirmación de una FAE mediante un test rápido o cultivo.

\section{Score de Wald}

Al igual que en los anteriores, se comprueba que la semiología no permite certificar la etiología estreptocócica de una FA, por muy "típica" que le parezca al examinador. A mayor puntaje (alta probabilidad de FAE), recomienda efectuar test rápido, a menor puntaje (baja probabilidad de FAE) basta con efectuar cultivo y esperar su resultado. (Tabla 4).

Valor predictor positivo para FAE en niños:

Score 4: $40 \%$

Score 5: 60\%

Score 6: $75 \%$

Tabla 2. Score de Centor para aproximarse a la etiología estreptocócica de una FA

Síntoma Puntaje

Temperatura $>38^{\circ} \mathrm{C}$

Ausencia de tos

Linfadenopatía cervical

Aumento de volumen amigdalino o exudado

ntaje

1

1

1

Puntaje total

Probabilidad de cultivo faríngeo positivo SBHGA (\%)

$\begin{array}{ll}0 & \sim 2,5 \\ 1 & \sim 6-7 \\ 2 & \sim 15 \\ 3 & \sim 30-35 \\ 4 & \sim 50-60\end{array}$

Tabla 3. Score de Mc Isaac para aproximarse a la etiología estreptocócica de una FA

\section{Criterio} Puntaje

Temperatura $>38^{\circ} \mathrm{C}$

1

Ausencia de tos

Linfadenopatía cervical sensible

1

Aumento de volumen amigdalino o exudado

1

Edad

$\begin{array}{lr}\text { 3-14 años } & 1 \\ 14-44 \text { años } & 0 \\ 44 \text { años o más } & -1\end{array}$

\begin{tabular}{rcl}
\hline Score & $\begin{array}{c}\text { Riesgo de infección } \\
\text { estreptocócica }\end{array}$ & Conducta sugerida \\
$\leq 0$ & $1-2,5 \%$ & No realizar estudio ni iniciar antimicrobianos \\
1 & $5-10 \%$ & \\
2 & $11-17 \%$ & Cultivar siempre \\
3 & $28-35 \%$ & Antibioterapia si el cultivo es positivo \\
$\geq 4$ & $51-53 \%$ & Tratar empíricamente con antimicrobianos y/o cultivar \\
\hline
\end{tabular}

Tabla 4. Score de Wald para aproximarse a la etiología estreptocócica de una FA

\begin{tabular}{lc}
\hline Parámetro & Puntaje \\
\hline Edad 5 -15 años & 1 \\
Mayo-noviembre (en Chile) & 1 \\
$\mathrm{t}^{\mathrm{O}}>38,3^{\circ} \mathrm{C}$ axilar & 1 \\
\hline Adenitis submaxilar & 1 \\
\hline Faringitis (eritema, exudado) & 1 \\
\hline Ausencia catarro r. alto & 1 \\
\hline
\end{tabular}


Si score supera 5 puntos, efectuar test rápido. Con 4 o menos, sólo cultivar.

\section{Diagnóstico microbiológico de FAE}

Simultáneamente con dos tórulas, se debe obtener muestra faríngea por hisopado enérgico de ambas amígdalas y la pared posterior de la faringe, con el propósito de realizar test rápido para $S$. pyogenes y cultivo faríngeo.

\section{Test rápidos}

- Requiere de una muestra obtenida con tórula seca y enviada al laboratorio, en breve, en un tubo estéril sin medio de transporte.

- Estos test se basan en la detección de antígenos bacterianos.

- Existen distintas técnicas: aglutinación con látex, inmunocromatografía (la más difundida), enzimoinmunoensayo.

- Resultado rápido (minutos, hasta aproximadamente 1 hora, según la técnica).

- Especificidad alta, desde 85 a 100\%, generalmente mayor a $95 \%$ (comparado con cultivo). Falsos positivos son una excepción (Streptococcus milleri).

- Sensibilidad variable, 97\% para inmunocromatografía.

- Mayor costo.

- Los estudios de concordancia diagnóstica muestran sensibilidad comparable entre enzimo-inmuno-ensayo e inmuno-ensayo óptico ( 85,4 versus $86,2 \%$ ), con una especificidad suficientemente elevada $(95,4 \%)$, permitiendo disminuir el uso innecesario de antimicrobianos y aumentando la proporción de pacientes con tratamiento adecuado.

\section{Cultivo faríngeo}

- Requiere introducir la segunda tórula en medio de transporte: Todd Hewitt, hasta su envío al laboratorio.

- Se debe sembrar la muestra en medio de cultivo agar sangre de cordero, cultivar a $35-37^{\circ} \mathrm{C}$. Lectura definitiva a las $48 \mathrm{~h}$. Puede obtenerse un informe preliminar presuntivo a las $24 \mathrm{~h}$.

- Estándar de oro para el diagnóstico.

- Sensibilidad: 90-95\% (si técnica de obtención de la muestra e incubación en laboratorio son adecuadas). Falsos negativos si se utilizó antimicrobianos previamente a la obtención de la misma.

- Menor costo.

- Mayor disponibilidad.

El cultivo es el único método recomendado para la pesquisa de portadores. Los test rápidos tienen sensibilidad variable, entre 70 y $90 \%$ y promedio de $85 \%$ (Cochrane Library 2016); la mayoría de los falsos negativos se describen en portadores, no recomendándose estas técnicas para la pesquisa de portación (ver párrafo sobre Recurrencias y estudio de portadores).

\section{Avances}

Se han incorporado pruebas diagnósticas rápidas que aplican técnicas como inmunoanálisis óptico, reacción de polimerasa en cadena y sondas de ADN quimioluminiscentes, con muy alta sensibilidad en comparación con el cultivo.

\section{Antiestreptolisina $O$ (ASO)}

Streptococcus pyogenes secreta la enzima estreptolisina $\mathrm{O}$, con capacidad hemolítica; esta enzima es, a la vez, un antígeno reconocido por el sistema inmune quien produce anticuerpos antiestreptolisina $\mathrm{O}$, detectables en el plasma aproximadamente un mes después de iniciada una infección estreptocócica. La detección de estos anticuerpos sugiere fuertemente la exposición a SGA; sin embargo, la intensidad de la respuesta inmune tiene variaciones individuales.

- Los títulos de ASO varían con la edad, ubicación geográfica, estacionalidad y sitio de infección. Una medición aislada requiere ser comparado con un valor basal previo o con el punto de corte superior normal en un área geográfica determinada (percentil 80, límite de referencia $<200 \mathrm{UI} / \mathrm{ml}$ ).

- Un aumento de cuatro veces el título entre fase aguda y convaleciente se acepta como significativo con un lapso de al menos dos semanas.

- Los títulos se elevan también en casos de infección por SBHGA con complicaciones no supurativas como fiebre reumática, glomerulonefritis post-estreptocócica, endocarditis y escarlatina.

- No está recomendado su uso en el diagnóstico de rutina de FAE, ya que refleja una infección reciente o pasada y no un evento en desarrollo. Estudios clínicos sugieren que aproximadamente entre 20 y $40 \%$ de los pacientes con FAE no adquieren una respuesta con anticuerpos ASO.

- Factores que interfieren en la síntesis de ASO son el uso temprano de antimicrobianos y la administración de corticosteroides, los que pueden disminuir los títulos de ASO

- Interferencias técnicas en la medición de títulos de ASO: bilirrubina $>60 \mathrm{mg} / \mathrm{dL}$, hemólisis con hemoglobina libre $>1 \mathrm{~g} / \mathrm{dL}$.

- Falsos positivos: infección por Streptococcus $\beta$ hemolítico no grupo A, particularmente por Streptococcus dysgalactiae subspecies equisimilis (Streptococcus grupo C y G de Lancefield), presencia de lipoproteínas séricas, reactividad cruzada (mieloma múltiple, hipergammaglobulinemia, insuficiencia hepática y enfermedades autoinmunes con factor reumatoideo elevado) y estado de portación de SBHGA. 


\section{Recomendaciones prácticas para el diagnóstico de FAE}

- Si se sospecha FAE siempre debe realizarse test de laboratorio (cultivo o test rápido) observando las recomendaciones de los scores de McIsaac o Wald mediante hisopado faríngeo, dado que las características clínicas por si solas no permiten discriminar con certeza entre FA causada por SBHGA versus viral. En niños y adolescentes, un resultado negativo de test rápido SBHGA debe ser confirmado con cultivo faríngeo negativo, para descartar una FAE.

- Si un test rápido resulta positivo, no es necesario la confirmación con cultivo, debido a su alta especificidad; los test rápidos no generan sobretratamiento (falsos positivos son excepcionales).

- No se recomienda realizar estudio para búsqueda de SBHGA en niños con características clínicas y epidemiológicas de faringitis aguda que sugieran fuertemente etiología viral (tos, coriza, disfonía, úlceras orales).

- Los test diagnósticos para SBHGA no están recomendados en niños bajo 3 años de edad, debido a la baja incidencia de FAE, presentación clásica infrecuente y la inusual ocurrencia de enfermedad reumática. Considere realizar test diagnósticos en este grupo etario si existen factores de riesgo, como hermanos mayores con infección por SBHGA.

- No se recomienda realizar test rápido ni cultivo, ni tampoco iniciar una profilaxis antiestreptocócica en contactos intradomiciliarios asintomáticos.

- No se recomienda repetir un test rápido ni el cultivo para el seguimiento post-tratamiento de una FAE.

\section{Tratamiento antimicrobiano}

Los pacientes con FAE deben ser tratados con el antimicrobiano apropiado, en dosis adecuadas, con una duración capaz de erradicar el microorganismo desde la faringe (10 días si ha de usarse un $\beta$ lactámico, macrólido o lincosamina).

Basado en su espectro de acción estrecho y dirigido, eventos adversos infrecuentes y costos, penicilina o amoxicilina son los fármacos de elección. No se ha descrito en el mundo resistencia in vitro de SBHGA a penicilina/amoxicilina.

En pacientes alérgicos a penicilina (hipersensibilidad no inmediata), el tratamiento de la FAE debe incluir una cefalosporina de primera generación por plazo de 10 días. En caso de corresponder a hipersensibilidad tipo 1 (anafilaxia), se recomienda prescribir clindamicina (lincosamina) por plazo de 10 días o azitromicina (azálida) durante 5 días.

En general, no hay riesgo en esperar 48-72 h el informe de un cultivo faríngeo para comenzar el tratamiento antimicrobiano.

\section{Opciones de antimicrobianos (Tabla 5)}

- Antimicrobianos con actividad in vitro contra SBHGA: penicilinas (ampicilina, amoxicilina, penicilinas semisintéticas), cefalosporinas, clindamicina, azálidas (azitromicina) y macrólidos.

- Penicilina: es el antimicrobiano de elección por su probada eficacia, seguridad, espectro reducido, bajo costo (su presentación oral no está disponible en Chile).

- Amoxicilina: posee eficacia comparable a penicilina oral.

\begin{tabular}{|c|c|c|}
\hline Antimicrobiano, vía de administración & Dosis & Duración \\
\hline \multicolumn{3}{|l|}{ Sin alergia a PNC } \\
\hline Amoxicilina, oral & $\begin{array}{l}50 \mathrm{mg} / \mathrm{kg} / \mathrm{día}, 1 \mathrm{vez} / \mathrm{día} \text { (máx }=1.000 \mathrm{mg} \text { ) } \\
\text { Alternativa: } 25 \mathrm{mg} / \mathrm{kg} / \text { dosis (máx }=500 \mathrm{mg} / \text { dosis), } 2 \text { veces } / \text { día }\end{array}$ & 10 días \\
\hline Penicilina benzatina, intramuscular & $\begin{array}{l}<27 \mathrm{~kg}: 600.000 \mathrm{UI} \\
\geq 27 \mathrm{~kg}: 1.200 .000 \mathrm{UI}\end{array}$ & 1 dosis \\
\hline \multicolumn{3}{|l|}{ Con alergia a PNC } \\
\hline Cefadroxilo*, oral & 30 mg/kg/día, 1 vez/día (máx = 1 g) & 10 días \\
\hline Clindamicina**, oral & $7 \mathrm{mg} / \mathrm{kg} /$ dosis, 3 veces $/$ día (máx $=300 \mathrm{mg} /$ dosis) & 10 días \\
\hline Azitromicina, oral & $\begin{array}{l}12 \mathrm{mg} / \mathrm{kg} / \mathrm{día}, 1 \mathrm{vez} / \mathrm{día}(\mathrm{máx}=500 \mathrm{mg}) \\
20 \mathrm{mg} / \mathrm{kg} / \mathrm{día}, 1 \mathrm{vez} / \mathrm{día}(\mathrm{máx}=500 \mathrm{mg})\end{array}$ & $\begin{array}{l}5 \text { días } \\
3 \text { días }\end{array}$ \\
\hline
\end{tabular}


- Penicilina benzatina intramuscular es una alternativa a 10 días de antimicrobianos orales. Tiene la mejor evidencia en prevención de enfermedad reumática. Obvia el aspecto adherencia al tratamiento.

- Cefalosporina de $1^{\circ}$ generación: son una alternativa a $\beta$-lactámicos si no existe hipersensibilidad inmediata (tipo 1) a penicilina. Por su facilidad de administración, generalmente se prefiere cefadroxilo.

- Azálidas y macrólidos: sólo se recomienda utilizarlos si existe antecedente de alergia a penicilina tipo 1 (anafilaxia).

- Clindamicina: utilizar si se conoce resistencia a macrólidos o alergia a penicilina, escasa disponibilidad y no se encuentra en formulación pediátrica en nuestro medio.

- Clindamicina y cefalosporinas de $1^{\circ}$ generación son las alternativas más efectivas en erradicar SBHGA en portadores.

\section{Duración y tasas de erradicación SBHGA}

- Los antimicrobianos se deben administrar en dosis y duración para erradicar SBHGA: 10 días (excepto penicilina benzatínica y azitromicina).

- La velocidad de erradicación bacteriana es de 48$72 \mathrm{~h}$.

- El tratamiento antimicrobiano con penicilina oral tiene $90 \%$ de éxito para erradicar SBHGA, puede ser mayor en prevenir la enfermedad reumática.

- Amoxicilina por 10 días logra 95-96\% de erradicación en niños, mientras que los macrólidos entre 84 y 95\%, según sea el esquema empleado.

- Con el uso de penicilina benzatina intramuscular se obtiene aproximadamente $80 \%$ de erradicación; sin embargo, no existen estudios recientes de tasas de erradicación en nuestro medio.

- Se han observado altas tasas de cura bacteriológica empleando tratamientos acortados con cefalosporinas de $1^{\circ}$ generación, pero la duración de 5 días es inferior a 10 días de penicilina.

- Tratamientos acortados de 5 días con cefalosporinas de amplio espectro y 3 a 5 días con azitromicina son efectivos en lograr erradicación bacteriana (95\%); sin embargo, no existe mayor beneficio con su uso y se asocian a mayor costo.

\section{Frecuencia de administración}

- Se recomiendan dosis única diaria o fraccionamiento cada $12 \mathrm{~h}$ para amoxicilina y cefalosporinas $1^{\circ}$ generación con eficacia probada en niños y adultos. Azitromicina se debe indicar una vez al día, como es usual.

\section{Beneficios de la antibioterapia}

El tratamiento antimicrobiano reduciría:
- La frecuencia de complicaciones supurativas; existe un plazo de 9 días para inicio de antimicrobianos sin incrementarse el riesgo de fiebre reumática.

- Duración de síntomas: la antibioterapia logra reducir la duración de la sintomatología en 8 a menos de $24 \mathrm{~h}$ (la afección es autolimitada); de acuerdo a una revisión Cochrane, se logra disminuir en $16 \mathrm{~h}$ la sintomatología.

- Transmisión a contactos: los pacientes dejan de contagiar después de 24 a 48 h, una vez iniciada una antibioterapia apropiada.

\section{Potenciales efectos adverso del uso de antibioterapia \\ - Hipersensibilidad}

- Inducción de resistencia en otras especies bacterianas en la comunidad. Se ha descrito la resistencia de S. pyogenes a macrólidos y azálidas, no así a $\beta$-lactámicos (ver párrafo Resistencia a antimicrobianos).

- Costos para el paciente.

\section{Resistencia antimicrobiana}

No se ha descrito resistencia de $S$. pyogenes a penicilina. Según los estudios de susceptibilidad para cepas invasoras en laboratorios de referencia nacional, se ha objetivado resistencia a eritromicina cercana a $6 \%$ y a clindamicina $3 \%$, similar a lo descrito en la literatura médica extranjera (en E.U.A. es $<8$ y $<2 \%$, respectivamente). A partir de la resistencia a eritromicina se puede extrapolar susceptibilidad al resto de los macrólidos (claritromicina, miocamicina) y a azitromicina, esta última preferida en casos de hipersensibilidad inmediata a $\beta$-lactámicos por su fácil adherencia y menores efectos gastrointestinales.

En un estudio nacional se encontró 3,5\% de resistencia para macrólidos (azitromicina, eritromicina y claritromicina) y $0,7 \%$ para clindamicina, a partir del análisis de 1.282 cepas de muestras clínicas de procesos invasores y no invasores entre 1998 y 2005 (C. Rodríguez et al, Rev Med Chile 2011; 139: 1143-9).

R. Camponovo y cols. describieron la susceptibilidad in vitro de $S$. pyogenes aislados de FAE en niños y adultos (n: 784 cepas) en Región Metropolitana entre 2009-2013, reportándose $4 \%$ de resistencia a eritromicina y $3 \%$ a clindamicina. (Figura 1).

Recientemente, el mismo grupo, (Camponovo y cols.), ha actualizado estos datos (años 2014-2017) (n: 884 cepas): penicilina $\mathrm{G}$ mantiene $\mathrm{S}$ de $100 \%$, clindamicina redujo su sensibilidad in vitro desde 93,3 a 81,6\%, y eritromicina lo hizo de 93,3 a 81,1\%.

En el análisis de susceptibilidad bacteriana a los antimicrobianos Red Salud UC 2012- 2015, se observa una 


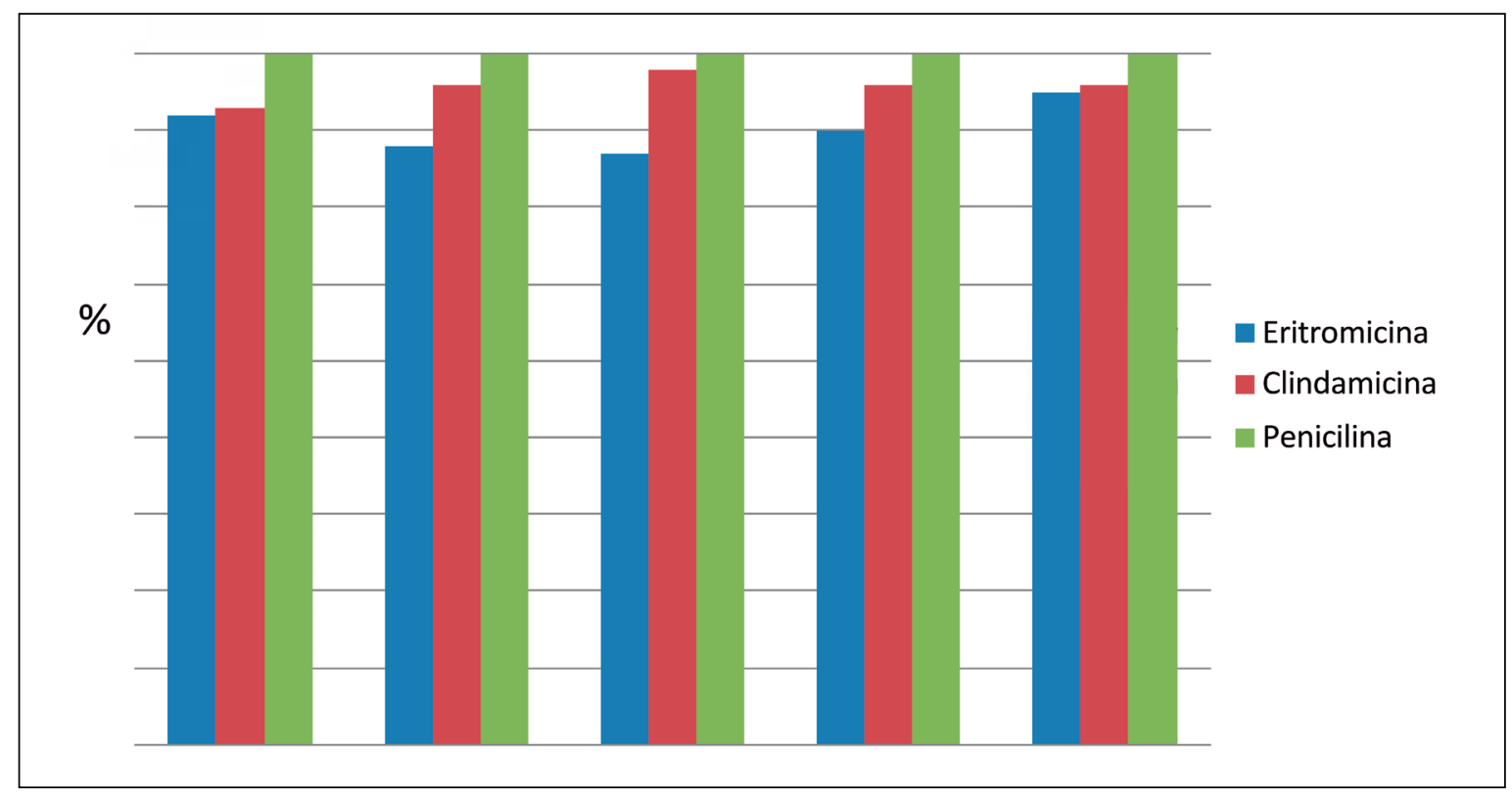

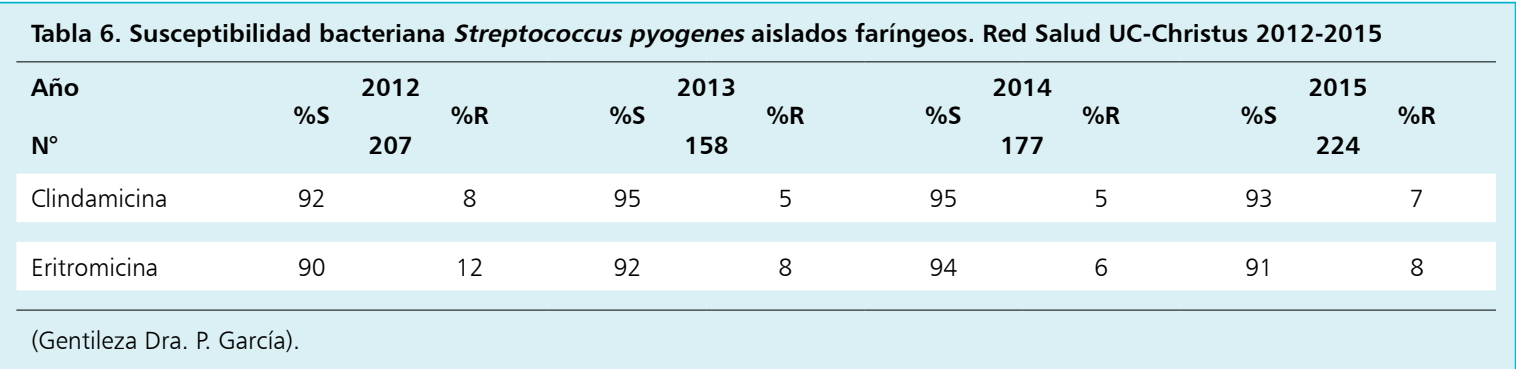

resistencia a macrólidos y clindamicina estable para las cepas de $S$. pyogenes de procedencia faríngea (Tabla 6).

Con todos los antecedentes aportados, es innecesario condicionar la selección del antimicrobiano a un informe de susceptibilidad in vitro de $S$. pyogenes. Se recomienda iniciar tratamiento empírico con un $\beta$-lactámico y sólo indicar tratamiento con azitromicina o macrólidos en casos de antecedente de anafilaxia a penicilina.

\section{Recurrencias y portadores}

- Los pacientes que desarrollen signos/síntomas de faringitis dentro de semanas o meses post-tratamiento asociado a evidencia de laboratorio de SBHGA, pueden corresponder a casos de FAE recurrente, así como también podría tratarse de cuadros virales a repetición en portadores crónicos faríngeos de SBHGA.

- Portadores crónicos: tienen muy bajo o nulo riesgo de complicaciones o diseminar la infección a contactos cercanos $(15 \%$ de los niños sanos son portadores crónicos o intermitentes, en ausencia de brote); por lo tanto, no se justifica su identificación y, generalmente, no requieren tratamiento antimicrobiano. Excepción a esta conducta, en opinión de expertos, es estudiar la portación en los contactos si existe entre ellos un paciente con antecedente de enfermedad reumática o glomerulonefritis post-estreptocócica o si se asiste a un "brote" de FAE confirmado bacteriológicamente en un grupo cerrado (familia o similar).

- Derivar a especialista (infectólogo, otorrinólogo) en cuadros de FAE debidamente documentadas, de curso recurrente.

\section{Prevención de la FAE}

- Contactos: no se recomienda estudio de rutina en contactos intradomiciliarios con FAE. Excepción: brotes y riesgo de secuelas por infección (glomerulonefritis y fiebre reumática), se debe erradicar.

- Cultivo seguimiento post-tratamiento sólo se justifica realizar si existe alto riesgo de fiebre reumática (áreas endémicas para FAE).
Figura 1. Susceptibilidad in vitro de $S$. pyogenes aislados de FA $(n=784)$. Región Metropolitana, Chile 20092013. (Datos Laboratorio Integramedica, Gentileza Dra. R. Camponovo). 


\begin{tabular}{|c|c|c|}
\hline & Recomendaciones & Errores frecuentes \\
\hline Diagnóstico & $\begin{array}{l}\text { - Siempre realizar confirmación mi- } \\
\text { crobiológica ante sospecha de FAE } \\
\text { de acuerdo a score (Centor, Mc } \\
\text { Isaac, Wald) }\end{array}$ & $\begin{array}{l}\text { - Iniciar antibioterapia empírica en FA } \\
\text { sin confirmación microbiológica } \\
\text { - Diagnóstico basado en la clínica }\end{array}$ \\
\hline $\begin{array}{l}\text { Estudio } \\
\text { microbiológico }\end{array}$ & $\begin{array}{l}\text { - Estudio con test rápido y/o cultivo } \\
\text { faríngeo* } \\
\text { - No realizar antibiograma (no existe } \\
\text { resistencia a penicilina) }\end{array}$ & $\begin{array}{l}\text { - Uso de ASO en etapa aguda de la } \\
\text { infección }\end{array}$ \\
\hline Tratamiento & $\begin{array}{l}\text { - Amoxicilina es la primera elección } \\
\text { - Solo uso de azálidas o macrólidos } \\
\text { en caso de hipersensibilidad tipo } 1 \\
\text { a penicilina (anafilaxia) } \\
\text { - Completar tratamiento } 10 \text { días para } \\
\text { lograr erradicación }\end{array}$ & $\begin{array}{l}\text { - Uso de azitromicina, macrólidos y } \\
\text { tratamientos acortados como pri- } \\
\text { mera elección }\end{array}$ \\
\hline Contactos & $\begin{array}{l}\text { - Estudio en caso de brotes y riesgo } \\
\text { de secuelas post-infección }\end{array}$ & - Estudio y tratamiento de contactos \\
\hline
\end{tabular}

- Tonsilectomía: no recomendado en forma aislada para reducir la frecuencia de FAE, debe ser un procedimiento excepcional.

- Vacunas: no disponibles.

\section{Complicaciones}

- Supurativas: absceso/flegmón periamigdalino, absceso retrofaríngeo, adenitis piógena, artritis séptica, neumonía, septicemia, endocarditis, fascitis necrosante, empiema subdural.

- No supurativas (postinfecciosas o mediadas por toxinas): escarlatina, fiebre reumática, artritis reactiva, glomerulonefritis postestreptocócica, shock tóxico, corea de Sydenham.

\section{Terapia adyuvante}

- AINES: Son más efectivos que paracetamol y placebo para el tratamiento de la fiebre y dolor asociada a FAE.

- Corticosteroides: proveen una pequeña reducción de los síntomas, no se recomienda su uso de rutina.

\section{Conclusiones}

- Destacable es una alta tasa de error utilizando sólo la manifestación clínica (50\% sensibilidad) en la toma de decisiones para indicar antibioterapia en una faringoamigdalitis aguda.

- Es recomendable el uso de test diagnóstico rápido y/o cultivo faríngeo en todo paciente con sospecha de FAE.

- Es necesario confirmar si una FA es causada por SBHGA o no; en la FAE el beneficio del tratamiento antimicrobiano en aliviar al paciente, terminar su contagiosidad y prevenir complicaciones está documentado.

- El beneficio de la antibioterapia es extensible a otras etiologías bacterianas de escasa incidencia y excepcional documentación, tales como A. hemolyticum, $C$. diphtheriae, C. pneumoniae y N. gonorrhoeae. Cada cual tiene su propia indicación que va más allá del foco de estas recomendaciones.

- Penicilina y amoxicilina constituyen tratamientos de elección.

- La resistencia in vitro de SBHGA a penicilina/amoxicilina es igual a CERO.

- La resistencia in vitro de SBHGA a clindamicina, macrólidos (y azálidas) en nuestro medio se ha elevado paulatinamente llegando en la actualidad a casi $20 \%$.

- Se deben balancear riesgos y beneficios al iniciar terapia antimicrobiana.

\section{Recomendaciones finales}

Ver Tabla 7.

\section{Lecturas recomendadas}

\section{Patogénesis}

- Lilja M, Räisänen S, Stenfors LE. Initial events in the pathogenesis of acute tonsillitis caused by Streptococcus pyogenes. Int J Pediatr Otorhinolaryngol 1998; 45 (1): 15-20. PMID: 9804015.

- Cywes C, Stamenkovic I, Wessels MR. CD44 as a receptor for colonization of the pharynx by group A Streptococcus. J Clin Invest 2000; 106 (8): 995-1002. DOI: 10.1172/JCI10195.

- Ryan P A, Pancholi V, Fischetti V A. Group A streptococci bind to mucin and human pharyngeal cells through sialic acid-containing receptors. Infect Immun 2001; 69 (12): 7402-12. DOI: 10.1128/IAI.69.12.74027412.200 .

- Kasper K J, Zeppa J J, Wakabayashi A T, Xu S X, Mazzuca D M, Welch I, et al. Bacterial superantigens promote acute nasopharyngeal infection by Streptococcus pyogenes in a human MHC Class II-dependent manner. PLoS Pathog 2014; 10 (5): e1004155. DOI: 10.1371/ journal.ppat.1004155. eCollection 2014 May. 


\section{Guías clínicas}

- Bisno A L, Gerber M A, Gwaltney J M Jr, Kaplan E L, Schwartz R H; Infectious Diseases Society of America. Practice guidelines for the diagnosis and management of group A streptococcal pharyngitis. Infectious Diseases Society of America. Clin Infect Dis 2002; 35 (2): 113-25. DOI: 10.1086/340949.

- Shulman S T, Bisno A L, Clegg H W, Gerber M A, Kaplan E L, Lee G, et al. Clinical practice guideline for the diagnosis and management of group A streptococcal pharyngitis: 2012 Update by the Infectious Diseases Society of America. Clin Infect Dis 2012; 55 (10): 1279-82. DOI: $10.1093 / \mathrm{cid} / \mathrm{cis} 847$.

- Group A streptococcal infections. Kimberlin D W, Brady M T, Jackson M A, Long SS, eds. Red Book: 2018 Report of the Committee on Infectious Diseases. 31st ed. Itasca, IL: American Academy of Pediatrics; 2018: 748-62.

\section{Artículos de Revisión}

- Wessels M R. Clinical practice. Streptococcal pharyngitis. N Engl J Med 2011; 364 (7): 648-55. DOI: 10.1056/NEJMcp1009126.

- Langlois D M, Andreae M. Group A streptococcal infections. Pediatr Rev 2011; 32 (10): 423-9. DOI: $10.1542 /$ pir.32-10-423.

- Kalra M G, Higgins K E, Pérez E D. Common questions about streptococcal pharyngitis. Am Fam Physician. 2016; 94 (1): 24-31. https:/www.aafp.org/ afp/2016/0701/p24.pdf.

\section{Diagnóstico}

- Centor R M, Witherspoon J M, Dalton H P, Brody C E, Link K. The diagnosis of strep throat in adults in the emergency room. Med Decis Making 1981; 1: 239-46. DOI:10.1177/0272989X8100100304.

- McIsaac W J, White D, Tannenbaum D, Low D E. A clinical score to reduce unnecessary antibiotic use in patients with sore throat. Can Med Assoc J 1998; 158 : 75-83. PMCID: PMC1228750.

- McIsaac W J, Goel V, To T, Low D E. The validity of a sore throat score in family practice. Can Med Assoc J 2000; 163: 811-5. PMCID: PMC80502.

- McIsaac W J, Kellner J D, Aufricht P, Vanjaka A, Low D E. Empirical validation of guidelines for the management of pharyngitis in children and adults. JAMA 2004; 291 (13): 1587-95. DOI: 10.1001/ jama.291.13.1587.
- Wald E R, Green M D, Schwartz B, Barbadora K. A streptococcal score card revisited. Pediatric Emergency Care 1998; 14 (2): 109-11. PMID:9583390.

- Shaikh N, Swaminathan N, Hooper E G. Accuracy and precision of the signs and symptoms of streptococcal pharyngitis in children: a systematic review. J Pediatr 2012; 160 (3): 487-93.e3. DOI: 10.1016/j. jpeds.2011.09.011.

- Cohen J F, Bertille N, Cohen R, Chalumeau M. Rapid antigen detection test for group A streptococcus in children with pharyngitis. Cochrane Database Syst Rev 2016; 7: CD010502. DOI: 10.1002/14651858. CD010502.pub2.

- Cohen J F, Cohen R, Levy C, Thollot F, Benani M, Bidet P, Chalumeau M. Selective testing strategies for diagnosing group A streptococcal infection in children with pharyngitis: a systematic review and prospective multicentre external validation study. Can Med Assoc J. 2015; 187 (1): 23-32. doi: 10.1503/cmaj.140772.

- Windfuhr J P, Toepfner N, Steffen G, Waldfahrer F, Berner R. Clinical practice guideline: tonsillitis I. Diagnostics and nonsurgical management. Eur Arch Otorhinolaryngol 2016; 273(4): 973-87. DOI: 10.1007/ s00405-015-3872-6.

\section{Tratamiento}

- Casey J R, Pichichero M E. Metaanalysis of short course antibiotic treatment for group A streptococcal tonsillopharyngitis. Pediatr Infect Dis J 2005; 24 (10): 909-17. PMID: 16220091.

- Spinks A, Glasziou P P, Del Mar C B. Antibiotics for sore throat. Cochrane Database Syst Rev 2013; (11): CD000023. DOI: 10.1002/14651858.

- Van Driel M L, De Sutter A I, Keber N, Habraken H, Christiaens T. Different antibiotic treatments for group A streptococcal pharyngitis. Cochrane Database Syst Rev 2013; (4): CD004406. DOI: 10.1002/14651858.

- Ng G J, Tan S, Vu A N, Del Mar C B, van Driel M L. Antibiotics for preventing recurrent sore throat. Cochrane Database Syst Rev 2015; (7): CD008911. DOI: $10.1002 / 14651858$.

\section{Resistencia antimicrobiana}

- Rodríguez C, Rojas P, Wozniak A, Kalergis A M, Cerón I, Riedel I, et al. Resistance phenotypes and genotypes of Streptococcus pyogenes clinical isolates in Chile over a 10-year period. Rev Med Chile 2011; 139 (9): 1143-9. DOI: /S0034-98872011000900005. 